data that provided correlations to the Pleistocene timescale.

Much to our surprise and the expectations for a slope dominated by erosion, the strata recovered at the four slope sites represent a complete record of stages 12-5.2 (474-122 ka). Nevertheless, slope deposition was influenced by global sea-level changes because Pleistocene mass-wasting deposits were associated with times of glacioeustatic lowerings.

Site 906 documented the remarkable history of a buried middle Miocene slope canyon. Seismic profiles show this feature is several times wider and more nearly flatfloored than canyons in this same region that formed in the Pleistocene. The actual origin of this buried feature is unclear, but the drilling results show that it formed between $\sim 13.5$ and $12.5 \mathrm{Ma}$ during an event that may correlate with an inferred glacioeustatic lowering.

Shortly after, the floor of the canyon was covered with debris shed from its own walls, and turbidites containing remarkably fresh quartz sand and wood fragments followed. These latter sediments were not found at other Leg 150 sites drilled outside this buried canyon, demonstrating that slope incisions enable turbidity currents to largely bypass the slope and leave very little sediment behind.

The end of the canyon phase was marked by rapid infilling with $100 \mathrm{~m}$ of laminated mud; this period represents an unusual interval of low bottom-water oxygen noted at other Leg 150 slope sites as well. The entire birth and demise of the canyon took less than $\sim 1$ m.y.

High surface water productivity occurred during the early to middle Miocene as indicated by diatom blooms, supply of abundant organic matter, and an interval of laminated sediments. Terrigenous supply greatly increased during the late middle to late Miocene, resulting in increased terrestrial organic carbon, generation of biogenic methane, reduction of pore water $\mathrm{pH}$, formation of pyrite, and dissolution of calcareous microfossils. At all of the slope sites we found abrupt salinity increases at the top of the Miocene. These high values (well above that of sea water) continued to increase with depth, suggesting the presence of underlying evaporite deposits.

Site 905 showed that mass wasting has occasionally been an important depositional agent on the upper continental rise. For example, the upper $212 \mathrm{~m}$ of sediment at this site comprise three separate mass flow units, all of which were deposited in the middle Pleistocene; in-place sediment between these units is no more than a few meters thick. Each mass flow deposit is made up of clasts derived from the adjacent continental slope. Some of the transported fragments reveal previous soft and brittle deformation, attesting to multiple mass wasting events.

At site 905 , bottom currents left their mark in the nearly $700 \mathrm{~m}$ of very uniform hemipelagic sediment recovered beneath the Pleistocene conglomerates. Erosional hiatuses at 4 and $9.5 \mathrm{Ma}$ confirm that intense thermohaline circulation events eroded the upper rise at the same time that DSDP sites 105 and 603 have shown they were removing sediment from the lower rise.

A microtektite layer in the upper Eocene at sites 903 and 904 correlates with a similar layer at site 612 and records the impact of an extraterrestrial body.

\section{Planning for the Future}

Onshore drilling is an important element of the transect strategy for learning about sea level history. Consequently, ODP is involved in a parallel program of drilling on the adjacent shoreline: $400+\mathrm{m}$ holes have been completed within the last year at Island Beach, Atlantic City, and Cape May N.J. (Figure 1).

Composition and ages across discontinuities at each site are providing crucial information about the time and extent of icehouse-age sea-level lowerings. These data make clear the need to recover the intervening shelf record; only then will it be possible to estimate the amplitudes and rates of sealevel change, and assess the full range of stratigraphic response of sequence architecture and facies succession to eustatic change. Planning for a return to the New Jersey margin has already begun.

\section{DOE National Lab Bill Passed \\ PAGE 209}

HR1432, the Department of Energy Laboratory Technology Act, was approved by the House Committee on Science, Space, and Technology on April 20. The bill redefines the role the laboratories play in meeting the needs of the nation during the next century.

The bill establishes well-defined missions for the national labs including dealing with national defense, energy security, environmental quality, and science. It also establishes the appropriate role of technology transfer, streamlines the process of technology transfer from the labs to the private sec tor, establishes a mechanism to evaluate laboratory performance, requires a plan for future use of DOE laboratories, and coordinates activities across the DOE lab system.

The bill also sets up a process for the review and evaluation of labs and the definition of their future roles. The review will result in a report to Congress on the capabilities of the labs, a process that DOE has started. There is also a provision for a government-wide lab review, involving labs in agencies other than DOE.

According to Committee Chairman George Brown (D-Calif.), "HR1432 ensures that the DOE laboratories will be in as good a position in 20 or 30 years as they are today to contribute to the research and development infrastructure of our country."

\section{Mesosphere-Lower Thermosphere Coupling}

\author{
PAGES 209-210
}

This piece was written to help inform science teachers, students, and journalists about some of the latest developments in the geophysical sciences. It will also appear in Earth in Space, published by AGU.

Unlike adjacent portions of the Earth's atmosphere, the mesosphere, at $\sim 60-100$ $\mathrm{km}$ altitude, is a region where relatively little direct solar energy is deposited. The extreme ultraviolet (EUV) component of sunlight is primarily absorbed above the mesosphere, and the ultraviolet (UV) component is absorbed below. Therefore the mesosphere may be likened to a giant atmospheric radiator, cooling continuously to space and replacing the lost energy via thermal conduction and poorly understood dynamical interactions.

The cooling rate is governed by radiative processes involving $\mathrm{CO}_{2}$, a gas whose global abundance is changing due to human activities. The balancing heating rate is controlled by the vertical thermal gradient, which is related to the depth of the mesospheric temperature minimum, and the degree of gravity wave and tidal activity.

In stark contrast to the mesosphere, the lower thermosphere, at $\sim 100-180 \mathrm{~km}$ altitude, is controlled by several competing, direct heating processes. Here energy deposition due to the effects of EUV absorption, magnetospheric auroral particle precipitation, and dissipation of electric currents in the local ionosphere arising from various sources all maximize.

Indeed, the high variability of the solar EUV flux [Lean, 1991] means that, at any given time, the lower thermosphere may be dominated by energy coming from the Sun, the magnetosphere, or the lower atmosphere. Of course, the latter two often dominate at high latitudes. Unraveling and interpreting the characteristic dynamical features of the lower thermosphere has become one of the most pressing issues in upper atmospheric science.

The close proximity of the cold radiating mesosphere with the highly variable lower thermosphere makes the "transition" zone between the two regions one of intense interest for atmospheric scientists. Significant observational impediments to the study of mesosphere-lower thermosphere coupling exist, due to the meager database of in situ satellite measurements currently available. Recent remote sensing measurements, how ever, together with sustained modeling efforts, are beginning to bear fruit.

Signatures of "breaking" gravity waves at mesopause altitudes $(\sim 90 \mathrm{~km})$ are of particular interest. These waves are generated at lower altitudes due to tropospheric effects, such as the passage of weather fronts and intense pressure regions. The waves propa- 
Eos, Vol. 75, No. 18, May 3, 1994
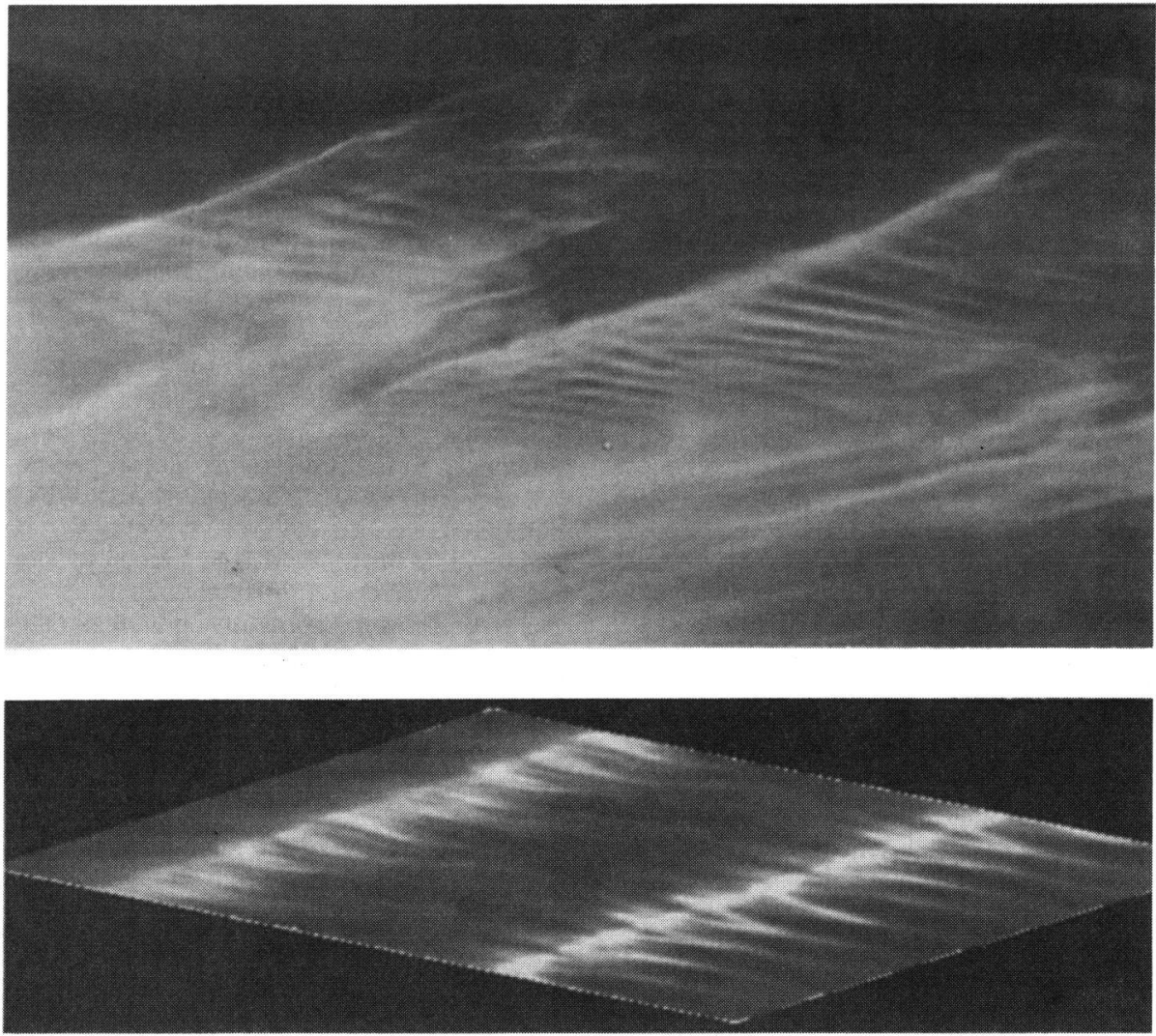

Fig. 1. Noctilucent clouds at $\sim 86 \mathrm{~km}$ altitude exhibit complex spatial structures (top) that can be modeled in terms of breaking gravity waves (bottom). (Taken from Fritts et al. [1993]).

gate upward and grow in amplitude until they reach a critical level near the mesopause where they "break," depositing energy and momentum.

Figure 1 [Fritts et al., 1993] shows a photograph of a noctilucent cloud at $\sim 86 \mathrm{~km}$ altitude, together with a numerical model calculation of breaking gravity waves near the mesopause. Noctilucent clouds are visible from the ground typically only near twilight during late summer months at high latitudes.

The clouds, which provide a screen on which the atmospheric waves in this region can be imaged, often exhibit wave structures that have multiple characteristic scales. The smallest scale waves (meters to kilometers) are thought to be the most important for forcing the mesosphere/lower thermosphere. Prevalent gravity waves have also been observed by lidars and all-sky cameras from the ground, from balloon-borne instruments, as well as from Shuttle-borne cameras. The ongoing work is motivated by the desire to develop a quantitative description of gravity wave spectra and occurrence frequencies, which will lead to a greater understanding of energy transport and coupling between regions.

Studies of the role of tides in mesosphere-lower thermosphere coupling have also progressed significantly. The atmospheric tides are coherent global oscillations driven by solar heating. Like gravity waves, these tides, which have periods of integer fractions or multiples of a day, propagate upward and dissipate in the lower thermosphere.

The long-term series of tidal measurements from ground-based radars is being supplemented by measurements of mesosphere winds from the upper atmosphere research satellites, showing surprising features like strong "planetary" waves with a period of about 2 days. As more investigators turn their attention to mesosphere/lower thermosphere dynamics, interesting 5-, 6- and 8-day waves are being reported, giving the impression that the mesosphere and lower thermosphere reacts like a "bowl of jelly," with multiple interacting modes of oscillation and coupling processes yet to be fully specified. These complex atmospheric motions are clearly responsible, at least in part, for the maintenance of the basic thermal structure of the Earth's upper atmosphere and, presumably, those of the other terrestrial-like planets.

While an understanding of the mesosphere and thermosphere and their interaction will probably not affect our ability to deal with more familiar atmospheric phenomena such as weather, it will have a direct impact on our lives through our use of the upper atmosphere in communications and through its role as a filter for particles and photons reaching the stratosphere where critical features like the ozone layer reside. It will also provide fundamental information on our most immediate interface with near-Earth space. It is in all respects "a new frontier."Timothy L. Killeen, University of Michigan, Ann Arbor

\section{References}

Fritts, D. C., J. R. Isler, and G. E.Thomas, Wave breaking signatures in noctilucent clouds, Geophys. Res. Lett., 20, 2039, 1993.

Lean, J., Variations in the Sun's radiative output, Rev. Geophys., 29, 505, 1991

\section{NOAA's Fleet Plan Available \\ PAGE 210}

Limited copies of NOAA's Fleet Replacement and Modernization Plan are available from the Marine Board, Commission on Engineering and Technical Systems, National Research Council, 2101 Constitution Ave., Washington, DC 20418.

The plan outlines NOAA's requirements for ships, ship design and acquisition, how to optimize investment for mission performance, and recommendations. It also gives detailed information about NOAA's ships, the fleet replacement and modernization budget, and the ship design and acquisition process.

\section{Remote Sensing System to Speed Disaster Relief PAGE 211}

NASA and the Federal Emergency Management Agency (FEMA) are exploring a cooperative venture to test and implement a prototype remote sensing system that will acquire, process, and distribute photographic-like digital images of disaster-damaged areas to response and recovery officials in near-real time.

"In past disasters, NASA's role has been to assist FEMA by providing aerial photographs to enhance their recovery operations and assessment of area damage. This joint venture will enhance the technology and process to enable FEMA, state, and local officials to obtain information more quickly to manage disaster recovery operations," says Fred Gregory of NASA.

The new system is designed to give response personnel critical information about the location and magnitude of a disaster within hours of acquisition instead of days or weeks. The system will utilize advanced imaging systems, a telemetry system to relay the images to the ground, and a mobile ground station to receive and construct aerial maps for use in the field.

Producing and distributing images of disaster sites using current technology is a slow and labor-intensive process requiring from 3 to 10 days to get an image to a geographical location. The process involves the acquisition of the image, relaying the image to the ground for processing, then distributing the image to rescue personnel. 